\title{
Effects of Temperature on Fatigue Crack Propagation in Pseudoelastic NiTi Shape Memory Alloys
}

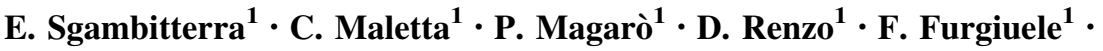 \\ H. Sehitoglu ${ }^{2}$
}

Published online: 26 August 2019

(C) ASM International 2019

\begin{abstract}
The effects of temperature on fatigue crack propagation in a pseudoelastic NiTi shape memory alloy (SMA) were analyzed. Single edge crack specimens were used and near crack tip displacements were captured by in situ digital image correlation (DIC). The effective stress intensity range was estimated from displacement data by a fitting procedure involving the William's solution. Stress intensity range was also estimated using a recent analytical model that accounts for the complex thermo-mechanical response of SMAs. In addition, comparisons with the linear elastic fracture mechanics (LEFM) solution were made. Results revealed an important role of temperature on crack propagation rate, that is, the higher the temperature the longer the fatigue life. However, it was demonstrated that these effects are attributed to the marked influence of temperature on near crack tip fields and, consequently, on the effective stress intensity range. This trend is correctly captured by the DIC method as well as by the analytical model. On the contrary, LEFM does not consider the effects of temperature and, consequently an apparent change in the material properties is observed. Therefore, a novel approach is proposed to analyze crack propagation in SMAs, where both stress and temperature are considered as significant loading parameters.
\end{abstract}

C. Maletta

carmine.maletta@unical.it

1 Department of Mechanical, Energy and Management Engineering, University of Calabria, Rende, Italy

2 Department of Mechanical Science and Engineering, University of Illinois at Urbana-Champaign, Illinois, USA
Keywords Shape memory alloys · NiTi alloys · Fatigue crack propagation - Digital image correlation - Overdeterministic method

\section{Introduction}

Nickel-Titanium (NiTi) shape memory alloys (SMAs) received great interest from both scientific and technical communities in the last years, due to their high shape recovery capabilities, by the so-called shape memory effect (SME) and pseudoelastic effect (PE) [1]. Thanks to these special functional properties, NiTi alloys have been becoming very attractive in different fields, starting from the consolidated market position in the biomedical field [2] to several emerging applications in automotive, aeronautic, aerospace, oil and gas and robotic sectors [3]. In most of these applications SMAs are subjected to cyclic and complex loads and, therefore, they are serious candidates for fatigue and fracture phenomena. However, it is widely accepted by the scientific community that standard procedures/methods based on classic solid mechanics theories cannot be directly applied to SMAs, due to their complex thermo-mechanical constitutive response associated with phase transformation mechanisms. In fact, at the crystallographic scale, the functional properties of SMAs are due to a reversible diffusionless phase transition, the thermoelastic martensitic transformation (TMT). A parent austenite (B2) phase is observed at high temperature, called austenite (B2), that is a relative ordered body centered cubic structure, and a less ordered monoclinic product phase at low temperature, called martensite $\left(\mathrm{B} 19^{\prime}\right)$. In addition, the martensitic phase can exhibit either a selfaccommodated microstructure at low stresses, i.e., with a mixture of different randomly distributed variants, or a 
reoriented structure at high stresses, that is obtained through the so-called detwinning reorientation mechanism. As a consequence, TMT can be induced either by temperature variations (Thermal Induced Martensite, TIM) or external stresses (stress-induced martensite, SIM), through a complex and hysteretic stress-strain-temperature response. Such a thermo-mechanical coupling significantly affects the crack formation and propagation phenomena, leading to unique fracture and fatigue responses.

Within this context, several researches were carried out in recent years with the aim of capturing the effects of stress- and/or thermally-induced phase transformations on both structural and functional fatigue properties of SMAs, as discussed in recent review papers [4-7]. Some of these studies were aimed at analyzing the low- and high-cycle fatigue properties and to define possible prediction methods, within the framework of standard approaches for common engineering alloys [8-13]. Other studies were focused on fracture-mechanics-based approaches to analyze the fatigue crack growth in SMAs, by considering the near crack tip transformation phenomena, as discussed in [14-16]. Some of these works were motivated by special/critical needs involving biomedical applications of NiTi SMAs, such as the endovascular stents [17-19].

It was always found that near crack tip microstructural transitions play a significant role on the evolution of both static and fatigue cracks. To better understand these features, special and/or ad-hoc investigation techniques were recently applied to directly analyze the local near crack tip transformations, such as the synchrotron X-ray microdiffraction (XRD) [20-24], infrared thermography (IR) $[25,26]$, and digital image correlation (DIC) [14, 26-31].

In particular, Robertson et al. [20] used in situ synchrotron X-ray diffraction to obtain the strain map in front of the crack subjected to fatigue loads. Synchrotron XRD was also used by Daymond et al. [21] to provide the twodimensional maps of elastic strain and texture ahead of crack tip and they concluded that detwinning of martensite twins occurs in front of the crack and in its wake after fatigue crack propagation. Gollerthan et al. [22], Ungár et al. [23] and Young et al. [24] analyzed the volume fraction of stress-induced martensite and the lattice strains in the crack tip region of compact tension specimens subjected to static loads. Dislocation plasticity and retained martensite were also captured after fracture.

IR measurements were made by Gollerthan et al. [25] to investigate the heat effects associated with the stress-induced martensite transformation in a pseudoelastic NiTi alloy during fatigue crack propagation. Maletta et al. [26] investigated the global and local temperature evolution in a pseudoelastic NiTi and tracked its trend during fatigue loading.
Daly et al. [27] used DIC technique to get the strain field in the proximity of the crack tip under mode I loading. Sgambitterra et al. [28-31] used the near crack tip displacement fields, measured by DIC, to estimate the effective stress intensity factor (SIF), by a numerical fitting of the William's series expansion [33]. More recently, a numerical procedure, based on a non-linear regression approach, was also developed in [32] to evaluate the effective SIF and the effective crack length in a single crystal NiTi alloy. Near crack tip transformation mechanisms were also analyzed by local mechanical measurements based on instrumented indentation [28, 34, 35]. In particular, the effects of testing temperature on the near crack tip stress-induced martensitic transformations were observed by analyzing the indentation response near the fracture zone.

All these experimental studies confirmed that highly localized stresses, arising at the crack tip region, generate texture evolutions induced by detwinning of martensite variants at the very crack tip. Such phenomena significantly affect the stress distribution and, consequently, they play a significant role on crack evolution mechanisms. These effects were studies by finite element (FE) method, with special constitutive models for SMAs [36-43] and by special analytical models [44-50], that are mainly based on modified linear elastic fracture mechanics (LEFM) concepts. In particular, a novel analytical method was developed in [47], based on a modified Irwin's correction of the LEFM [33], that allows to predict the extent of crack tip transformation region as well as the actual stress distribution.

However, despite the large number of research reports on both static and fatigue cracks in NiTi SMAs, only a few studies reported the effects of the testing temperatures $[16,30,51,52]$ within the pseudoelastic regime. In fact, most of the literature studies assume that fracture and fatigue properties depend only on the crystallographic state of the alloy and, therefore, comparison between martensite, austenite, and stable austenite are given.

Baxevanis et al. [51] investigated the toughening loss due to thermo-mechanical coupling in mode I fracture. Baxevanis and Lagoudas [16] pointed out that the effect of the loading rate, that is linked to the latent heat of transformation, is a relevant issue for fracture of NiTi. You et al. [52] analyzed the influence of the loading frequency and the resulting temperature change on the crack growth rate. They showed that crack growth rate is significantly dependent on the loading frequency. Maletta et al. [30] demonstrated a marked temperature effect on the fracture response of a NiTi alloy within the pseudoelastic regime. It was shown that temperature plays an important role on SIF and on fracture toughness parameters, because it 
significantly affects the crack tip transformation behavior and the resulting stress-strain distribution.

For this reason, fatigue crack propagation experiments were carried out in this investigation with the aim of analyzing the effects of temperature on crack growth rate in NiTi SMAs, within the pseudoelastic regime. In particular, isothermal fatigue tests were carried out, by using eccentrically loaded single edge crack (ESE) specimens made of a commercial pseudoelastic NiTi alloy, according to the E647 ASTM Standard [53]. The DIC technique was also applied to measure the near crack tip displacement and the obtained data were used to estimate the effective SIF, by a numerical fitting procedure involving the William's series solution [33]. The effective propagation curve of the alloy was calculated accordingly. Furthermore, the experimental results were analyzed by using a recent analytical model $[47,48]$. It was demonstrated that this model is able to correctly capture the effects of temperature on the crack tip stress distribution.

\section{Materials and Methods}

\section{Material and Specimen}

A commercial Ni rich NiTi alloy $(50.8$ at. $\% \mathrm{Ni}-49.2$ at.\% Ti, Type S, SAES Memry, USA) was analyzed in this investigation. Figure 1a illustrates the isothermal quasistatic strain controlled stress-strain curves of the alloy, at three values of the temperature $\left(T=25{ }^{\circ} \mathrm{C}, 45{ }^{\circ} \mathrm{C}, 65^{\circ} \mathrm{C}\right)$ within the pseudoelastic regime, i.e., $A_{\mathrm{f}}<T<M_{\mathrm{d}}$. The measured values of the main mechanical parameters are also shown in the figure: transformation stresses at $T_{0}=25{ }^{\circ} \mathrm{C}\left(\sigma_{\mathrm{s} 0}^{\mathrm{AM}}, \sigma_{\mathrm{f} 0}^{\mathrm{AM}}, \sigma_{\mathrm{s} 0}^{\mathrm{MA}} \sigma_{\mathrm{f} 0}^{\mathrm{MA}}\right)$, transformation strain

(a)

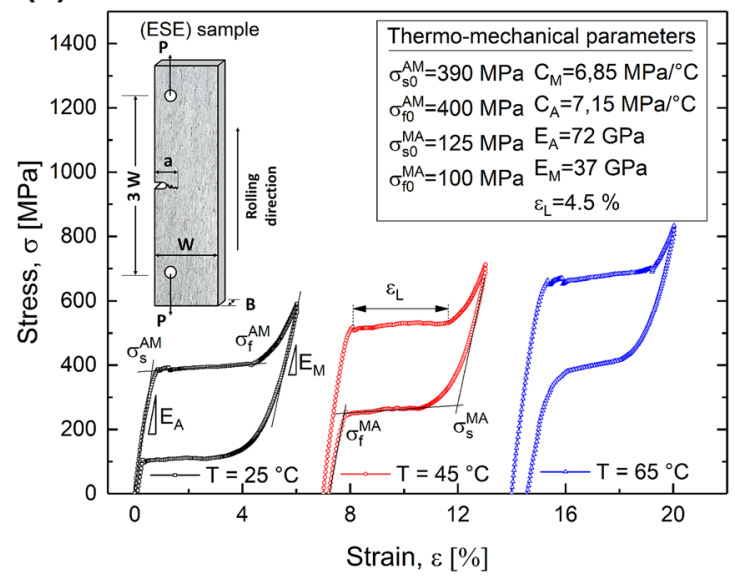

Fig. 1 a Isothermal stress-strain response of the alloy at three testing temperatures $\left(T=25{ }^{\circ} \mathrm{C}, 45{ }^{\circ} \mathrm{C}\right.$ and $\left.65^{\circ} \mathrm{C}\right)$ with the main mechanical parameters and the geometry of eccentrically loaded single edge crack
$\left(\varepsilon_{\mathrm{L}}\right)$, Young's moduli $\left(E_{\mathrm{A}}, E_{\mathrm{M}}\right)$ and Clausius-Clapeyron constants $\left(C_{\mathrm{A}}, C_{\mathrm{M}}\right)$. Figure $1 \mathrm{~b}$ shows the differential scanning calorimetry (DSC) thermogram of the alloy $\left(T= \pm 100^{\circ} \mathrm{C}, \dot{T}=10^{\circ} \mathrm{C} / \mathrm{min}\right)$ together with the measured transformation temperatures $\left(M_{\mathrm{s}}, M_{\mathrm{f}}, A_{\mathrm{s}}, A_{\mathrm{f}}\right)$.

Eccentrically loaded single edge crack (ESE) specimens with a width $W=12 \mathrm{~mm}$ (see Fig. 1a) were manufactured from as-received cold-rolled pseudoelastic NiTi plates with thickness $B=0.5 \mathrm{~mm}$, by electro discharge machining (EDM). The rolling direction is parallel to the loading axis.

Isothermal fatigue crack propagation tests were carried out at the three testing temperatures of Fig. 1a $(25,45$ and $65^{\circ} \mathrm{C}$ ). Load controlled tests were executed at a frequency $f=5 \mathrm{~Hz}$, with a load ratio $R=\sigma_{\min } / \sigma_{\max }=0.05$ and a maximum nominal stress $\sigma_{\max }=16 \mathrm{MPa}$. Nominal stress was calculated from the applied load $(P)$ assuming the whole cross section of the uncracked specimen $(W B)$. The samples were previously fatigue pre-cracked starting from the EDM notch $(r=100 \mu \mathrm{m})$, up to a length to width ratio $(a / W)$ around 0.20 , by using a lower value of the maximum stress $\left(\sigma_{\max }=10 \mathrm{MPa}\right)$, as suggested by the ASTM E647 standard. Almost straight crack paths normal to the load direction, initiating from the EDM notch, were always obtained.

The tests were carried out by an electro-dynamic testing machine (Instron E10000) equipped with a $10 \mathrm{kN}$ load cell. A special system was developed to control the temperature during the experiment. It is made of a Peltier cell, directly applied on one side of the specimen, a K-type thermocouple glued on the other side and a control unit. Crack propagation and evolution was monitored in situ during mechanical tests by a CCD Camera (Sony ICX 625Prosilica GT 2450) with a resolution of $2448 \times 2050$ pixels. A suitable objective was adopted to focus the crack

(b)

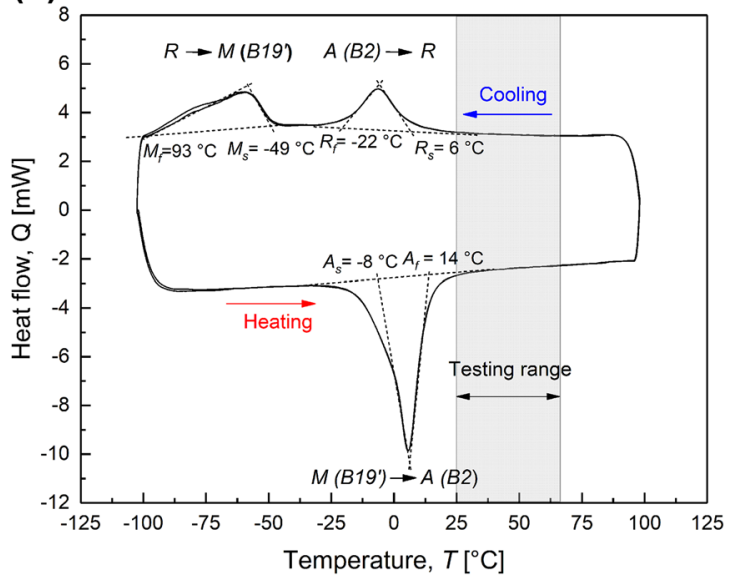

(ESE) specimen; b differential scanning calorimetry (DSC) thermogram of the alloy with the measured values of the transformation temperatures (TTs) 
tip region (Rodagon f. $80 \mathrm{~mm}$-Rodenstock), resulting in a resolution of 450 pixels $/ \mathrm{mm}$. Loading frequency was periodically decreased to $0.5 \mathrm{~Hz}$ for a few cycles to capture a significant number of digital images to be used for the correlation analyses made by a commercial software (VIC$2 \mathrm{D}^{\circledR}$, Correlated Solutions).

\section{Stress Intensity Factors in SMAs: Basics}

As well known, large non-linearity could occur in the crack tip region due to stress-induced transformations, as schematically shown in Fig. 2. This results in a fully transformed martensitic region at the very crack tip, identified by the radius $r_{\mathrm{M}}$, a partially transformed region, between $r_{\mathrm{M}}$ and $r_{\mathrm{A}}$, and an untransformed region beyond $r_{\mathrm{A}}$. This causes a complex stress distribution, as schematically depicted in the figure, and, consequently, LEFM approaches fail in predicting the stress intensity factor. As a consequence, the stress intensity range $\left(\Delta K_{\mathrm{I}}\right)$ experienced during crack propagation was calculated by three different methods as described in the following sections: (1) the standard ASTM E647 method [53], (2) the analytical method by Maletta et al. [47, 48], and (3) a regression method based on the DIC displacement field.

\section{ASTM E647 Method}

The mode I stress intensity range, $\Delta K_{\mathrm{I}}$, under the condition of small-scale transformation [50], i.e., in the predominantly elastic regime, can be calculated according to the standard ASTM E647 [53]:

$\Delta K_{\mathrm{ILEFM}}=\frac{\Delta P}{B \sqrt{W}} F$

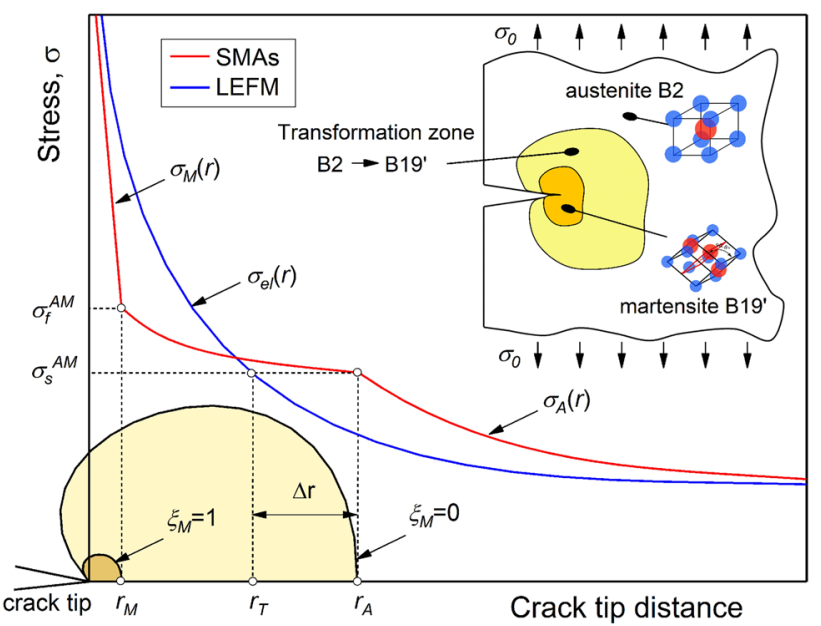

Fig. 2 Schematic depiction of the crack tip stress distribution and transformation region in SMAs

$$
\begin{aligned}
F= & \alpha^{1 / 2}(1.4+\alpha)(1-\alpha)^{-3 / 2} G \\
G= & 3.97-10.88 \alpha+26.25 \alpha^{2}-38.9 \alpha^{3}+30.15 \alpha^{4} \\
& -9.27 \alpha^{5} \\
\alpha= & a / W
\end{aligned}
$$

The predominantly elastic condition must be verified by the following equation [53]:

$$
(W-a) \geq \frac{4}{\pi}\left(\frac{K_{\mathrm{Imax}}}{\sigma_{\mathrm{s}}^{\mathrm{AM}}}\right)^{2}
$$

where $(W-a)$ is the uncracked ligament and the term at the right end side is a measure of the extent of the crack tip transformation zone. The equation is obtained from ASTM E647 by substituting the yield strength $\left(S_{Y}\right)$ with the transformation stress $\left(\sigma_{\mathrm{s}}^{\mathrm{AM}}\right)$. However, it is worth noting that condition (5) becomes temperature dependent in a pseudoelastic SMA, due to the Clausius-Clapeyron relation:

$\sigma_{\mathrm{s}}^{\mathrm{AM}}=\sigma_{\mathrm{s} 0}^{\mathrm{AM}}+C_{\mathrm{M}}\left(T-T_{0}\right)$

where $\sigma_{\mathrm{s} 0}^{\mathrm{AM}}$ is the transformation stress at the reference temperature $T_{0}$. Figure 3 reports a graphical illustration of Eq. (5). In particular, the left-side term, the uncracked ligament $(W-a)$, and the right-side term are plotted together as a function of the stress intensity factor for the three investigated values of the temperature. The intersection points between the curves represent the upper bounds for the stress intensity factor, namely $K_{\text {Iel }}$, defining the predominantly elastic region. It is shown that $K_{\text {Iel }}$ increases with the testing temperature, due to the decreased transformation zone, and it ranges from about $22 \mathrm{MPa} \mathrm{m}^{1 / 2}$ at $25^{\circ} \mathrm{C}$ to $28 \mathrm{MPa} \mathrm{m}^{1 / 2}$ at $45^{\circ} \mathrm{C}$ and $33 \mathrm{MPa} \mathrm{m}^{1 / 2}$ at $T=65^{\circ} \mathrm{C}$.

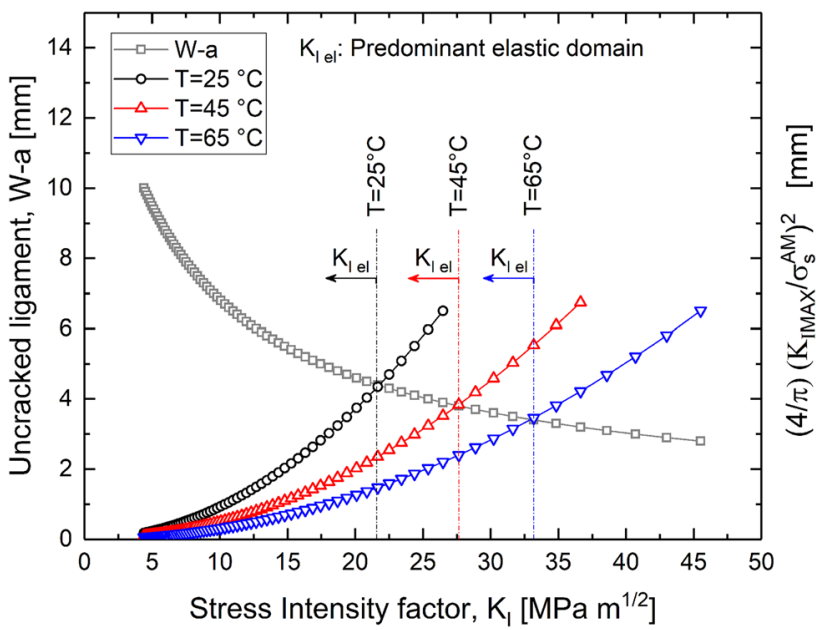

Fig. 3 Conditions given by ASTM E647 standard for predominantly elastic domain for the three investigated temperatures 


\section{Analytical Method}

The stress intensity range was calculated by the modified LEFM analytical model proposed by Maletta et al. [47]. In the following, a basic description of the analytical method is reported for the sake of completeness. The method allows to predict the crack tip transformation mechanisms, the stress and strain distributions, and the resulting stress intensity factor.

In particular, in the case of mode I loading, the martensitic and austenitic radii $\left(r_{\mathrm{M}}\right.$ and $r_{\mathrm{A}}$ ) are given by:

$r_{\mathrm{M}}=\frac{2}{\pi}\left(\frac{(1-v-b v)(1-b) K_{\mathrm{Ie}}}{(1-b) E_{\mathrm{A}} \varepsilon_{\mathrm{L}}+(b+1)(1-2 v) \sigma_{\mathrm{f}}^{\mathrm{AM}}+(1-b) \sigma_{\mathrm{s}}^{\mathrm{AM}}}\right)^{2}$

$$
\begin{aligned}
& r_{\mathrm{A}}=\frac{2(1-b) K_{\mathrm{Ie}}^{2}}{\pi \sigma_{\mathrm{s}}^{\mathrm{AM}}\left(\sigma_{\mathrm{s}}^{\mathrm{AM}}+\sigma_{\mathrm{f}}^{\mathrm{AM}}\right)} \\
& +\frac{2\left(E_{\mathrm{A}} \varepsilon_{\mathrm{L}}+\alpha_{\mathrm{M}}^{-1} \sigma_{\mathrm{f}}^{\mathrm{AM}}-\sigma_{\mathrm{s}}^{\mathrm{AM}}\right) r_{\mathrm{M}}+4(1-v-b v) K_{\mathrm{Ie}} \sqrt{2 r_{\mathrm{M}} / \pi}}{(1-b) \alpha_{\mathrm{M}}^{-1}+(b+1)(1-2 v)\left(\sigma_{\mathrm{s}}^{\mathrm{AM}}+\sigma_{\mathrm{f}}^{\mathrm{AM}}\right)}+r_{\mathrm{M}}
\end{aligned}
$$

where $\alpha_{\mathrm{M}}=E_{\mathrm{M}} / E_{\mathrm{A}}$ is the Young's modulus ratio, $v$ is the Poisson's ratio, $b=0$ for plane stress and $b=2 v$ for plane strain, $K_{\mathrm{Iel}}$ is the effective stress intensity factor, i.e., it is related to the effective crack length $a_{\mathrm{e}}$, similarly to the Irwin's correction of the LEFM.

The crack tip stress distribution in both austenitic and martensitic regions $\left(\sigma_{\mathrm{A}}\right.$ and $\sigma_{\mathrm{M}}$ ) can be obtained from equilibrium and compatibility equations:

$\sigma_{A i}(r)=g_{i} \frac{K_{\mathrm{Ie}}}{\sqrt{2 \pi(r-\Delta r)}}$

$\sigma_{\mathrm{Mi}}(r)=g_{i} \frac{2(1-v-b v) K_{\mathrm{Ie}} / \sqrt{2 \pi r}-E_{\mathrm{A}} \varepsilon_{\mathrm{L}}+\alpha_{\mathrm{M}}^{-1} \sigma_{\mathrm{f}}^{\mathrm{AM}}-\sigma_{\mathrm{s}}^{\mathrm{AM}}}{(1-b) \alpha_{\mathrm{M}}^{-1}+(b+1)(1-2 v)}$

where $g_{i}=1$ for $i=1,2$ and $g_{i}=b$ for $i=3$. The mode I austenitic SIF, namely $K_{\mathrm{IA}}$, can be directly obtained from stress distribution (Eq. 9) by considering the distance from the effective crack tip $(\widetilde{r}=r-\Delta r)$, according to the Irwin's assumption:

$K_{\mathrm{IA}}=\lim _{r \rightarrow 0} \sqrt{2 \pi \widetilde{r}} \sigma_{\mathrm{A}}=K_{\mathrm{Ie}}$

The mode I martensitic SIF, namely $K_{\mathrm{IM}}$, can be obtained from Eq. (10):

$K_{\mathrm{IM}}=\lim _{r \rightarrow 0} \sqrt{2 \pi r} \sigma_{\mathrm{M}}=\frac{2(1-v-b v)}{(1-b) \alpha_{\mathrm{M}}^{-1}+(b+1)(1-2 v)} K_{\mathrm{Ie}}$

Equation (12) shows that $K_{\mathrm{IM}}$ can be expressed as a function of $K_{\mathrm{IA}}$ by a material constant coefficient. However, it is worth noting that the knowledge of the extent of transformation region, in terms of both $r_{\mathrm{M}}$ and $r_{\mathrm{A}}$, is required to calculate $K_{\mathrm{IA}}$ and $K_{\mathrm{IM}}$ by an iterative approach, similarly to the Irwin's correction for elastic-plastic materials.

\section{Regression Method}

The effective stress intensity factor defining the actual crack tip displacement field was estimated from a regression analysis of the DIC measurements, by the William's expansion series [33], based on the method described in [32]. The analytical solution of the near crack tip displacement field $\{\boldsymbol{u}\}=\left\{\begin{array}{ll}u_{x} & u_{y}\end{array}\right\}^{T}$, for an isotropic material under mode I loading, is given by:

$$
\begin{aligned}
\{\boldsymbol{u}\} & =[\boldsymbol{\psi}]\{\boldsymbol{U}\} \\
& =\left[\begin{array}{lllll}
\psi_{11} & \psi_{12} & \psi_{13} & 1 & 0 \\
\psi_{21} & \psi_{22} & \psi_{23} & 0 & 1
\end{array}\right]\left\{\begin{array}{lllll}
K_{\mathrm{I}} & T & A & B_{x} & B_{y}
\end{array}\right\}^{T}
\end{aligned}
$$

where $K_{\mathrm{I}}$ is the mode I stress intensity factor, $T$ is the $\mathrm{T}$ stress parameter, $A$ is the rigid body rotation term, $B_{x}$ and $B_{y}$ are the rigid body motions along $x$ and $y$ axis. The functions $\psi_{i j}$ can be expressed in terms of the polar coordinate centered at the crack tip $\left(x_{0}, y_{0}\right)$ as shown in Fig. 4:

$$
\left\{\begin{array}{l}
\psi_{11}=\frac{1}{\mu} \cdot \sqrt{\left(\frac{r}{2 \pi}\right)} \cdot \cos \left(\frac{\theta}{2}\right)\left[\frac{1}{2}(k-1)+\sin ^{2}\left(\frac{\theta}{2}\right)\right] \\
\psi_{21}=\frac{1}{\mu} \cdot \sqrt{\left(\frac{r}{2 \pi}\right)} \cdot \sin \left(\frac{\theta}{2}\right)\left[\frac{1}{2}(k+1)-\cos ^{2}\left(\frac{\theta}{2}\right)\right] \\
\psi_{22}=-\frac{v r}{2 \mu(1+v)} \cdot \sin \theta \\
\psi_{12}=\frac{r}{2 \mu(1+v)} \cdot \cos \theta \\
\psi_{13}=-r \cdot \sin \theta \\
\psi_{23}=r \cdot \cos \theta
\end{array}\right.
$$

where $\mu=E /[2(1+v)]$ is the shear modulus of elasticity and $k=(3-v) /(1+v)$ for plane stress and $k=(3-4 v)$ for plane strain. The $T$-stress parameter, that is the second order term of the William's expansion series, was included because of the large fracture process zone in SMAs, associated with near crack tip stress-induced transformations [29]. In fact, the size of the investigation windows should be larger than the $K$-dominant zone and, consequently, $T$-stress term becomes a non-negligible parameter.

If Eq. (13) is applied to the $m$ measurement points of the DIC a system of $2 \mathrm{~m}$ linear equations is obtained:

$\left\{\boldsymbol{u}^{*}\right\}=\left[\boldsymbol{\psi}^{*}\right]\{\boldsymbol{U}\}$ 


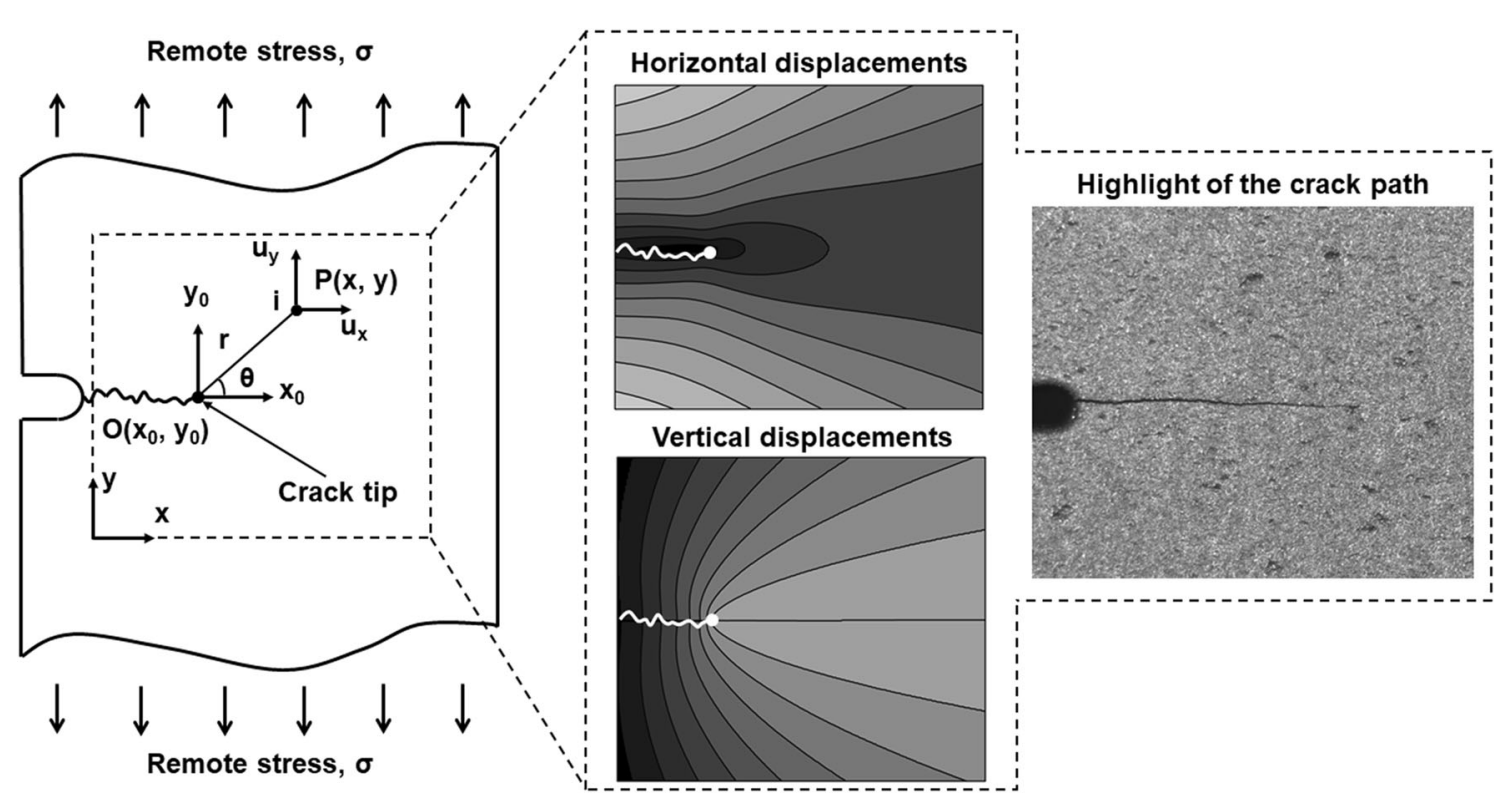

Fig. 4 Schematic depiction of a single edge crack subjected to a remote stress, together with the corresponding near crack tip horizontal and vertical displacements

where $\left[\psi^{*}\right]$ is a $2 m \times 5$ matrix obtained by computing the matrix $[\boldsymbol{\psi}]$ of Eq. (13) in the $m$ points and the vector $\left\{\boldsymbol{u}^{*}\right\}$ contain the corresponding $2 \mathrm{~m}$ displacement components.

Equation (15) represents an overdetermined system of linear equations, i.e., with five unknowns and $2 \mathrm{~m}$ equations, and the least square method can be used the obtain an estimate of the unknown parameters $\{\boldsymbol{U}\}$, by the pseudoinverse of the matrix $\left[\boldsymbol{\psi}^{*}\right]$ :

$\{\boldsymbol{U}\}=\left(\left[\boldsymbol{\psi}^{*}\right]^{T}\left[\boldsymbol{\psi}^{*}\right]^{-1}\right)\left[\boldsymbol{\psi}^{*}\right]^{T}\left\{\boldsymbol{u}^{*}\right\}$

It is important to note that Eq. (16) can be solved only if the coordinates of the physical crack tip $\left(x_{0}, y_{0}\right)$ are known. These latter can be identified from the high-resolution images captured during crack propagation. However, the physical crack tip location does not always give the best fit of the linear solution of Eq. (16), as the crack tip nonlinearities cause a stress-strain redistribution. This can be taken into account by an effective crack length $a_{\mathrm{e}}$, as described in the analytical model of the previous section.

In particular, the higher the stress intensity factor the larger the non-linear effects and the errors in the $K_{\mathrm{I}}$ estimates. To overcome this limitation, the coordinates of the effective crack tip, namely $\left(x_{\mathrm{e}}, y_{\mathrm{e}}\right)$, must be considered as unknown parameters in Eq. (13), i.e., they have to be included in a new vector of unknowns:

$\{\boldsymbol{U}\}=\left\{\begin{array}{lllllll}K_{\mathrm{I}} & T & A & B_{x} & B_{y} & x_{\mathrm{e}} & y_{\mathrm{e}}\end{array}\right\}^{T}$

However, this leads to a system of non-linear equations and, consequently, a non-linear fitting procedure must be used [32]. In particular, the vector of unknowns $\{\boldsymbol{U}\}$ is calculated by an iterative procedure based on NewtonRaphson method. To this aim, Eq. (13) can be written as a series of iterative equations based on Taylor's series expansions as follows:

$\{\boldsymbol{u}\}_{i+1}=\{\boldsymbol{u}\}_{i}+\sum_{n=1}^{7}\left[\frac{\partial\{\boldsymbol{u}\}}{\partial U_{n}} \Delta U_{n}\right]_{i}=\{\boldsymbol{u}\}_{i}+\nabla\{\boldsymbol{u}\}_{i}\{\Delta \boldsymbol{U}\}_{i}$

where the subscript $i$ indicates the $i$-th iteration step, $\nabla\{\boldsymbol{u}\}$ is the gradient $(2 \times 7$ matrix $)$ with respect to the unknown terms $\quad\{\boldsymbol{U}\} \quad$ and $\quad\{\Delta \boldsymbol{U}\}_{i}=\left\{\Delta K_{\mathrm{I}} \quad \Delta T \quad \Delta A\right.$ $\left.\Delta B_{x} \Delta B_{y} \Delta x_{\mathrm{e}} \Delta y_{\mathrm{e}}\right\}_{i}^{T}$ is the correction to the estimation of the vector $\{\boldsymbol{U}\}$ at the $i$-th step.

Equation (18) can be rewritten in terms of the correction of the displacement vector at the $i$-th step, namely $\{\Delta \boldsymbol{u}\}_{i}=\{\boldsymbol{u}\}_{i+1}-\{\boldsymbol{u}\}_{i}$ :

$\{\Delta \boldsymbol{u}\}_{i}=[\xi]_{i}\{\Delta \boldsymbol{U}\}_{i}$

where the matrix $[\xi]_{i}(2 \times 7)$ represents the gradient of the displacement vector $\{\boldsymbol{u}\}_{i}$. If Eq. (19) is applied to the $m$ measurements points and the displacement vector at the $i+1$ step is set to the experimental one $\left(\left\{\Delta \boldsymbol{u}^{*}\right\}_{i}=\left\{\boldsymbol{u}^{*}\right\}-\{\boldsymbol{u}\}_{i}\right)$ the following overestimated system of $2 m$ equations is obtained:

$\left\{\Delta \boldsymbol{u}^{*}\right\}_{i}=\left[\xi^{*}\right]_{i}\{\Delta \boldsymbol{U}\}_{i}$

where $\left[\xi^{*}\right]_{i}$ is a $2 m \times 7$ matrix obtained by computing the 
matrix $[\xi]_{i}$ of Eq. (19) in the $m$ points. Least squares regression gives the best fit of $\{\Delta \boldsymbol{U}\}_{i}$ :

$\{\Delta \boldsymbol{U}\}_{i}=\left(\left[\xi^{*}\right]_{i}^{T}\left[\xi^{*}\right]_{i}\right)^{-1}\left[\xi^{*}\right]_{i}^{T}\left\{\Delta \boldsymbol{u}^{*}\right\}_{i}$

The solution of the system gives the correction vector of unknowns for prior estimates of the coefficients. Accordingly, an iterative procedure is used to obtain the best-fit set of coefficients, i.e., the procedure described above is repeated until the corrections $\{\Delta \boldsymbol{U}\}_{i}$ become acceptably small.

Systematic studies were carried out to analyze the effects of crack tip non-linearity on the estimates of unknowns $\{\boldsymbol{U}\}$, and in particular on mode I SIF and effective crack length, by using both linear and non-linear regression methods. Figure 5 reports the differences between linearly and non-linearly regressed SIF, namely $\delta K_{\mathrm{I}}=K_{\mathrm{I}}^{\mathrm{L}}-K_{\mathrm{I}}^{\mathrm{NL}}$, as a function of the effective SIF obtained from non-linear regression. The application ranges of the two methods are also highlighted, for the three different values of the temperature, when considering a maximum allowable difference of $5 \%$. In particular, it is shown that non-linear regression should be used when $K_{\mathrm{I}}$ is higher than around $8 \mathrm{MPa} \mathrm{m}^{1 / 2}, 12 \mathrm{MPa} \mathrm{m}^{1 / 2}$, and $20 \mathrm{MPa} \mathrm{m}{ }^{1 / 2}$ at $25^{\circ} \mathrm{C}, 45^{\circ} \mathrm{C}$, and $65^{\circ} \mathrm{C}$, respectively.

Figures 6 and 7 give further insight into the effects of crack tip non-linearity by the two regression methods. In particular, Fig. 6 represent the case of low SIF value $\left(K_{\mathrm{I}}=8 \mathrm{MPam}^{1 / 2}\right.$ at $T=25^{\circ} \mathrm{C}$ ) whereas Fig. 7 are relative to high SIF values $\left(K_{\mathrm{I}}=20 \mathrm{MPam}^{1 / 2}\right.$ at $\left.T=25{ }^{\circ} \mathrm{C}\right)$.

Figure 6 a shows a comparison between the measured vertical displacements (blue contours) with the corresponding regressed data (red contours) obtained from the linear regression method, i.e., by considering the physical

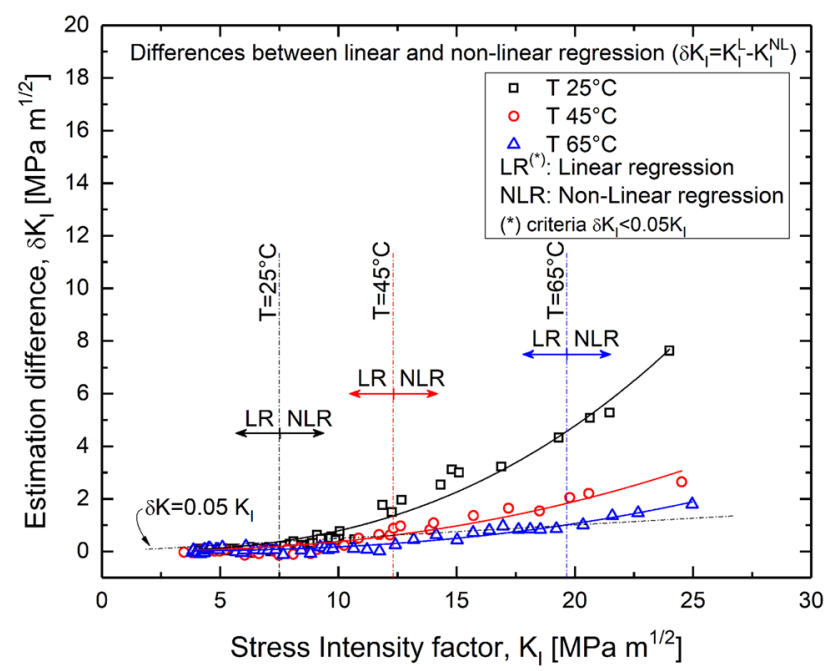

Fig. 5 Differences between linearly and non-linearly regressed SIF as a function of the effective stress intensity factor crack tip location $\left(x_{0}, y_{0}\right)$. A good agreement is shown due to the small transformation zone, that is the effective crack tip $\left(x_{\mathrm{e}}, y_{\mathrm{e}}\right)$ is very close to the physical one. This result is also evident from Fig. 6b, where the near crack tip vertical stress component $\sigma_{y}$, as a function of the distance from the crack tip and for $\theta=0$, is shown. In particular, experimental data, obtained by the generalized Hooke's law and DIC strain field, are compared with the asymptotic LEFM solution. A good agreement is observed with the clear evidence of a vertical asymptote near the physical crack tip. As a consequence, under such condition, the linear regression method can be used to estimate fracture parameters.

The scenario appears to be significantly different when increasing the SIF as shown in Fig. 7. Figure 7a shows a comparison between the experimentally measured displacement and the solution obtained from linear regression that uses the physical crack tip as input parameter. Results show that matching between the two solutions is inaccurate. Figure $7 b$, instead, shows that the best fit is obtained with the non-linear regression solution, that uses an effective crack length higher than the physical one. Some mismatch only exists at the very crack tip where marked local non-linearity cause significant deviation with respect to LEFM as also evident from the measured strain maps shown in Fig. 7c.

This effect is also highlighted in Fig. 7d that reports the vertical stress components obtained from DIC together with the asymptotic solutions obtained by considering the physical and effective crack tip location. Two vertical asymptotes are observed, defining the stress distributions in the austenitic untransformed region and in the fully transformed martensitic region, as predicted by our analytical model (see Fig. 2). In such condition, the linear regression solution provide inaccurate results and the non-linear method (Eq. 21) must be used.

\section{Results and Discussions}

\section{Crack Tip Strain Field and Transformation Zone}

Figures 8 show the near crack tip von Mises strain contours $\left(\varepsilon_{V M}\right)$, obtained from DIC measurements at the maximum applied stress $\left(\sigma_{\max }=16 \mathrm{MPa}\right)$ and for different values of the temperature and crack length. In particular, Fig 8a and b show the strain distribution for a crack length ratio $a /$ $W=0.54$ at $T=25{ }^{\circ} \mathrm{C}$ and $65^{\circ} \mathrm{C}$, respectively. Figure $8 \mathrm{c}$ and $\mathrm{d}$ illustrate the same results at a smaller crack length ratio $(a / W=0.32)$.

As expected, the longer the crack and the lower the temperature, the higher the near crack tip strain, due to the 
(a)

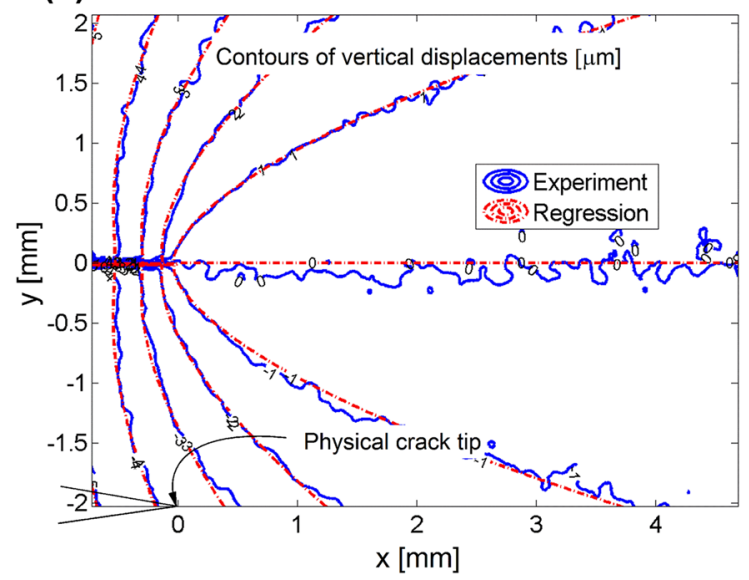

Fig. 6 Results of linear regression model for small SIF values $\left(K_{\mathrm{I}}=8 \mathrm{MPa} \mathrm{m}{ }^{1 / 2}\right.$ at $\left.T=25^{\circ} \mathrm{C}\right)$ : a comparison of vertical displacement contours between DIC measurements and regressed data;

(a)

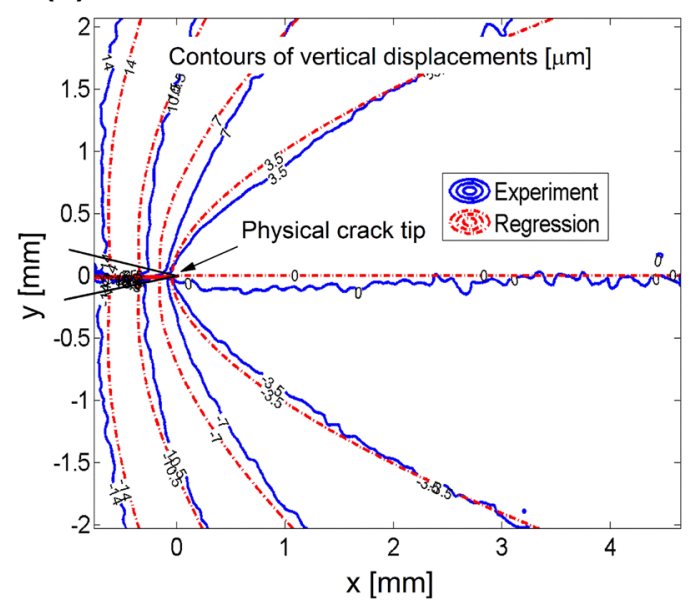

(c)

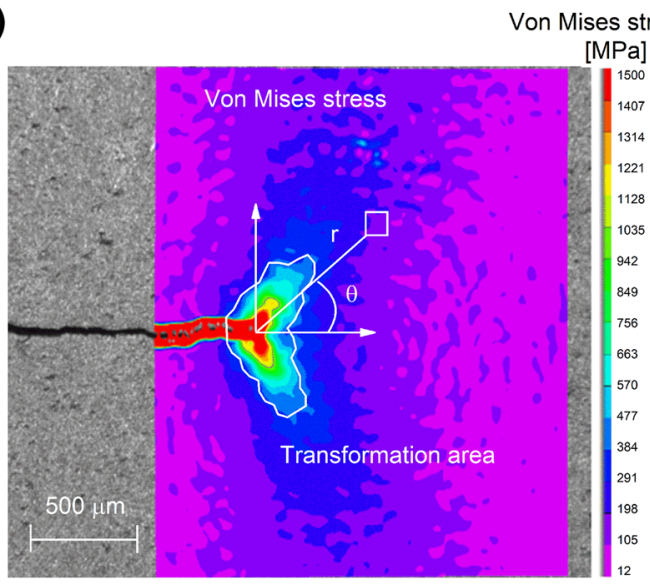

Fig. 7 Results of non-linear regression method for high SIF values $\left(K_{\mathrm{I}}=20 \mathrm{MPam}^{1 / 2}\right.$ at $\left.T=25^{\circ} \mathrm{C}\right)$ : a comparison of vertical displacement contours between DIC and linear regression results; $\mathbf{b}$ comparison of vertical displacement contours between DIC measurements

\section{(b)}

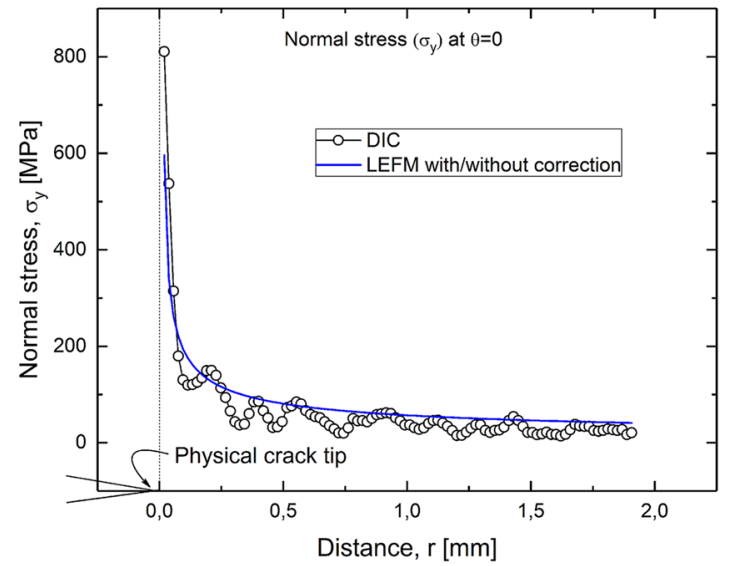

b comparison of the normal stress $\left(\sigma_{\mathrm{y}}\right)$ profile, at $\theta=0$, between DIC results and LEFM predictions

(b)

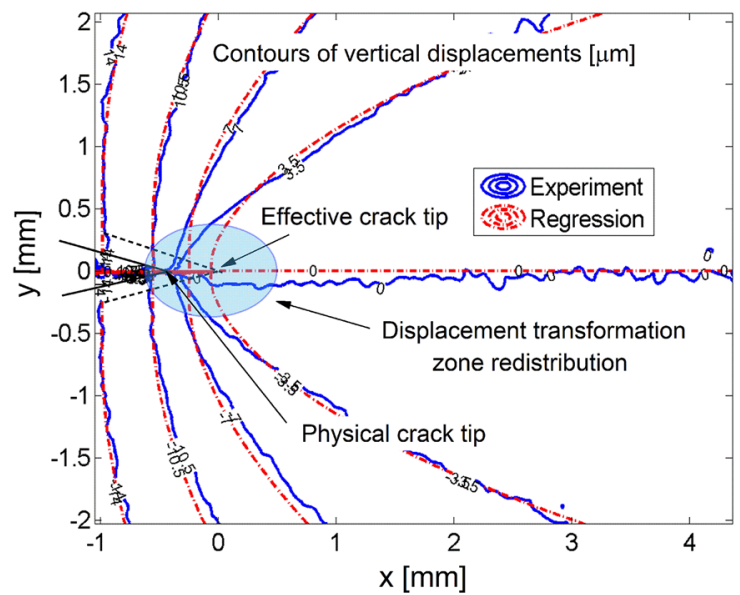

(d)

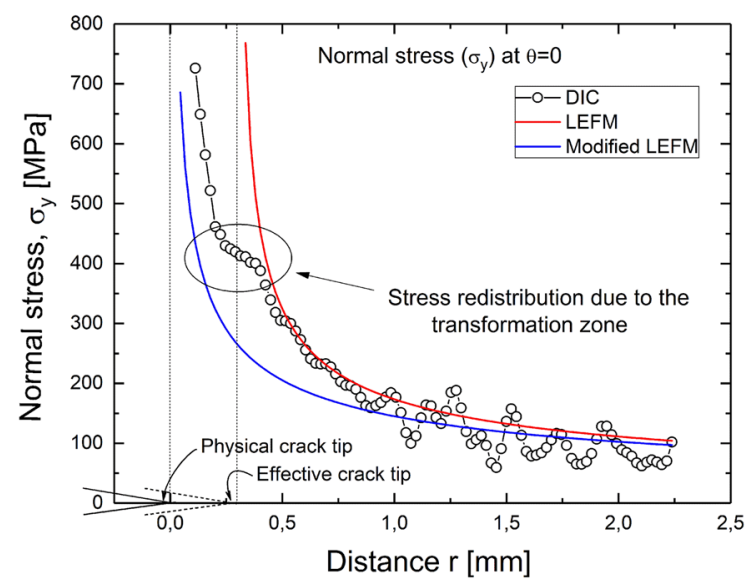

and non-linear regression results; c Von Mises stress map calculated from the DIC strain results; d comparison of the normal stress $\left(\sigma_{y}\right)$ distribution $(\theta=0)$ between DIC and LEFM methods 


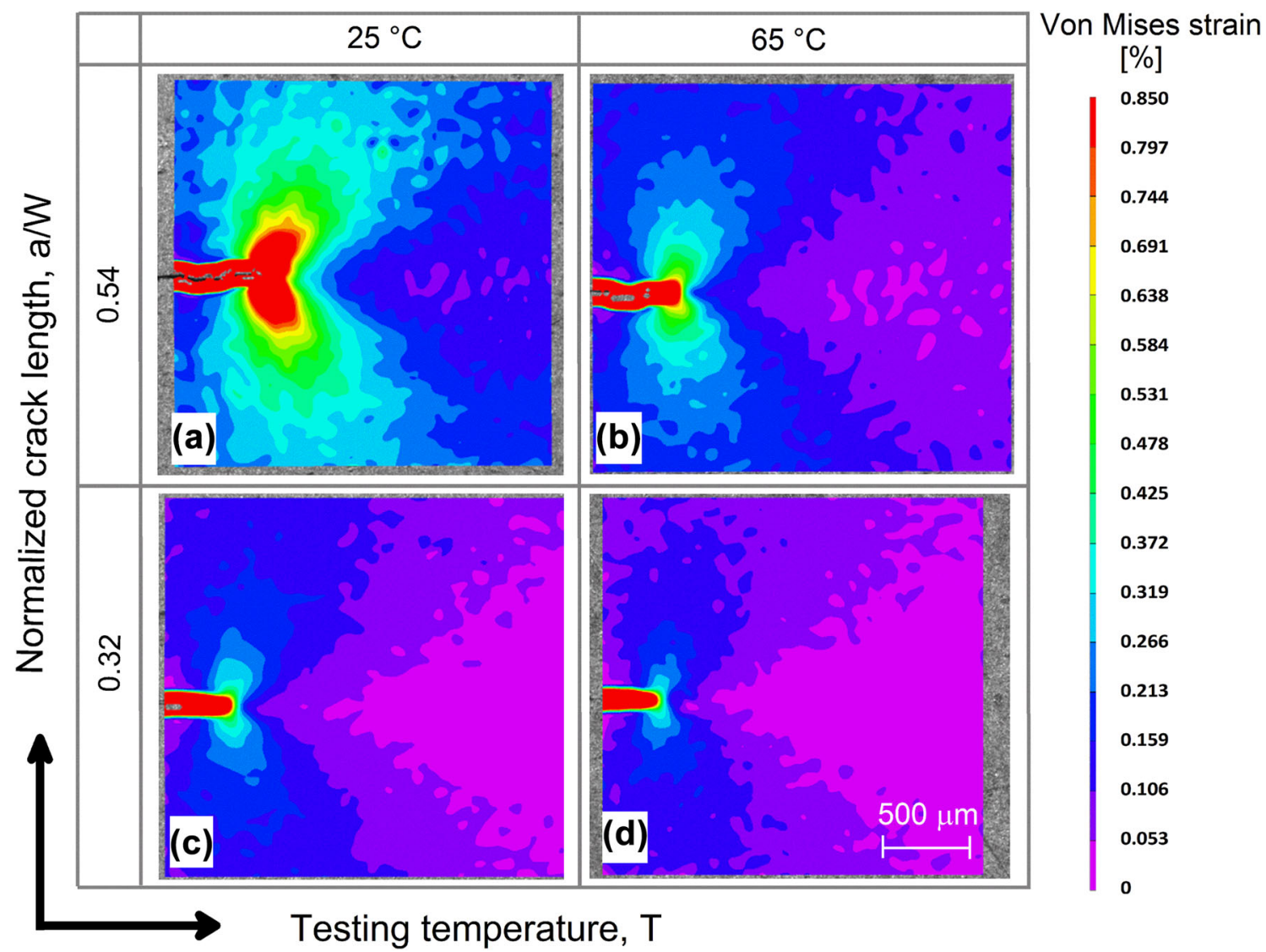

Fig. 8 Von Mises strain maps obtained from DIC measurements at different crack length ratios $(a / W)$ and temperatures $(T)$ : a $a / W=0.54$ and $T=25{ }^{\circ} \mathrm{C} ; \mathbf{b} a / W=0.54$ and $T=65{ }^{\circ} \mathrm{C} ; \mathbf{c} a / W=0.32$ and $T=25{ }^{\circ} \mathrm{C} ; \mathbf{d} a / W=0.32$ and $T=65^{\circ} \mathrm{C}$

increased transformation zone, as highlighted by the red maps in the figures $\left(\varepsilon_{V M}>0.85 \%\right)$. In fact, the transformation zone is proportional to the parameter $\left(K_{\mathrm{I}} / \sigma_{\mathrm{s}}^{\mathrm{AM}}\right)^{2}$.

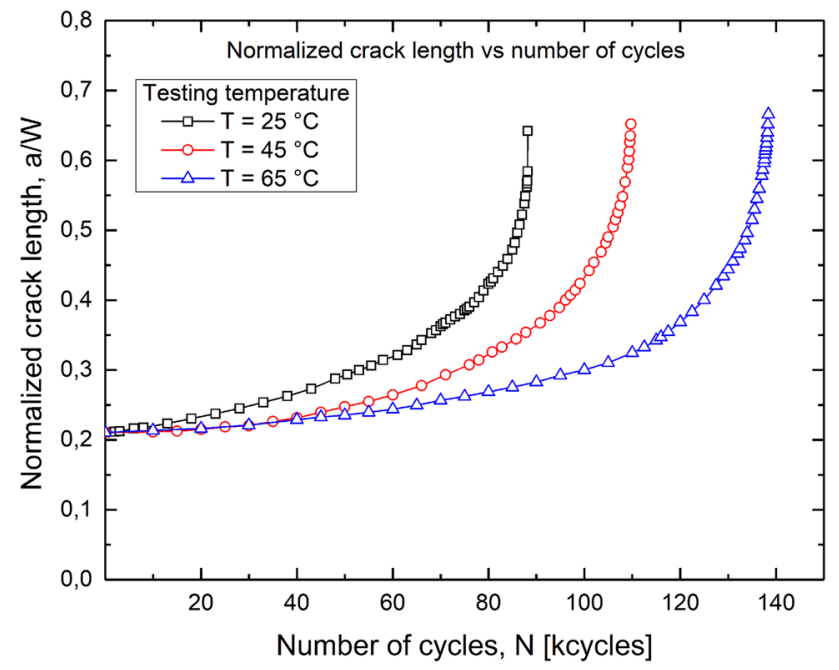

Fig. 9 Evolution of the normalized crack length, $a / W$, as a function of the number of cycles for the three testing temperatures $\left(25^{\circ} \mathrm{C}\right.$, $45{ }^{\circ} \mathrm{C}$ and $\left.65^{\circ} \mathrm{C}\right)$
As a consequence, the temperature plays a very important role, according to the Clausius-Clapeyron relation (Eq. 6), especially when considering large cracks $(a / W=0.54)$, whereas less evident effects are observed for smaller cracks, due to the reduced SIF values.

\section{Fatigue Crack Propagation}

Figure 9 reports the evolution of the crack length during fatigue propagation experiments for the three testing temperatures, starting from an initial crack length to width ratio $(a / W)$ around 0.2 .

It was found that the propagation rate decreases when increasing the testing temperature resulting in a longer fatigue life. This is attributed to the marked effects of the temperature on the crack tip transformation mechanisms and resulting stress/strain fields, as discussed in the previous section. In fact, as directly demonstrated in previous studies [20-24], pseudoelastic SMAs always exhibit a martensitic microstructure at the very crack tip below the martensite desist temperature $\left(T<M_{\mathrm{d}}\right)$ and, therefore, difference in the crack propagation mechanisms is attributed to different stress/strain fields. Similar results have been also observed 


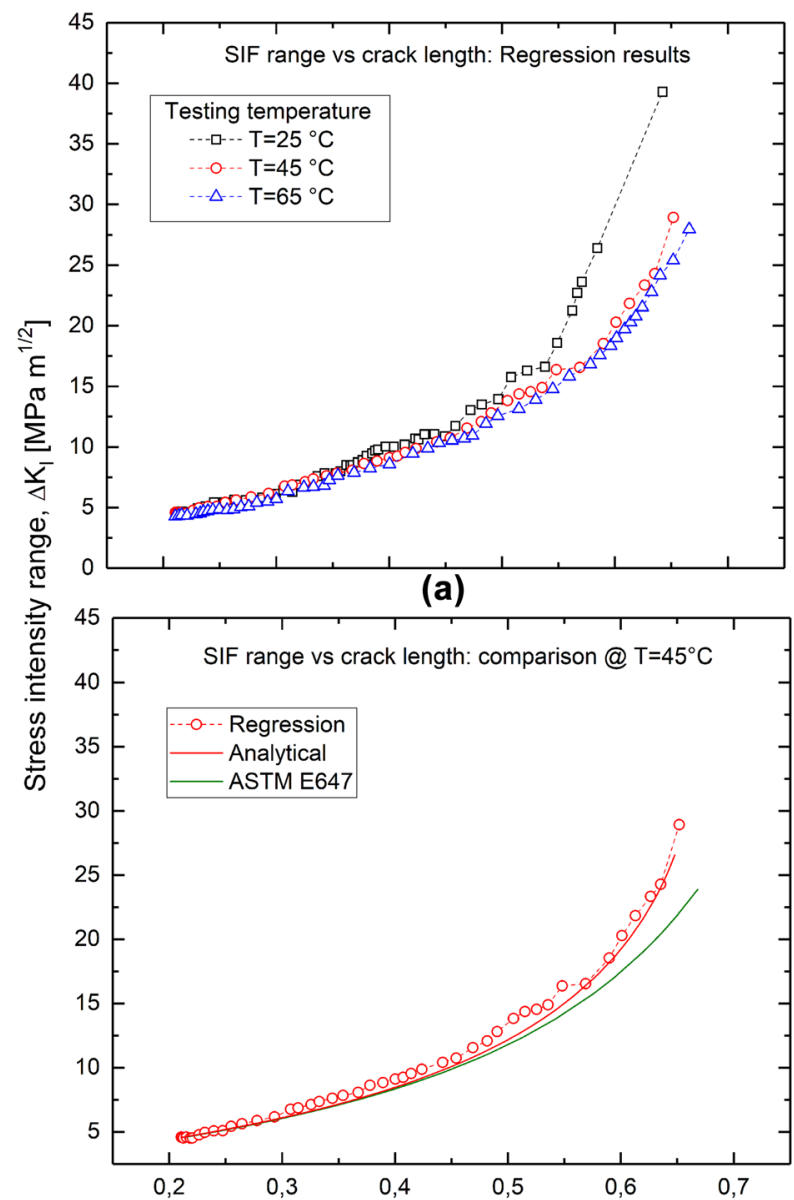

(c)

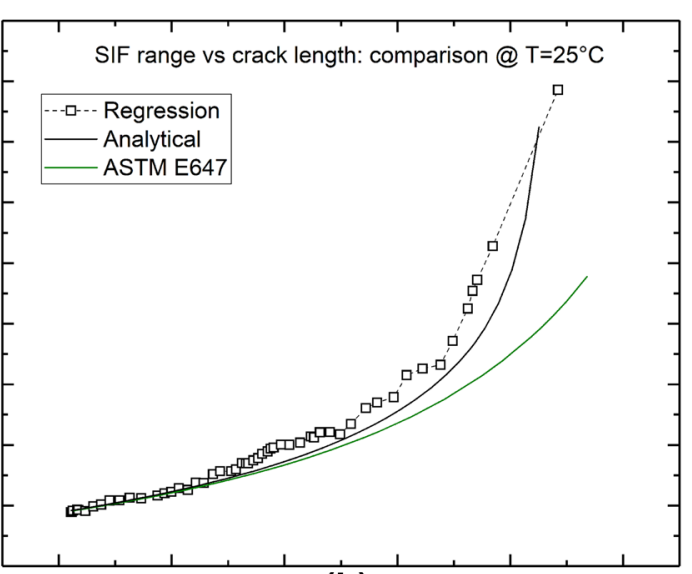

(b)

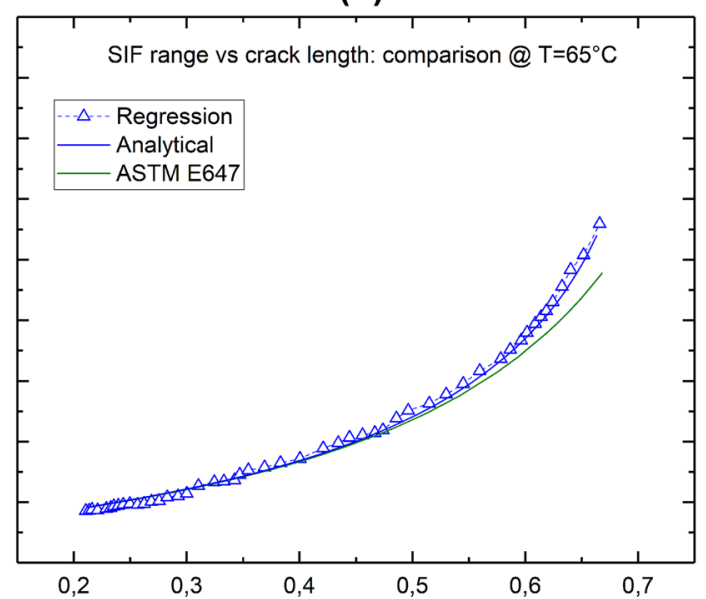

(d)

Normalized crack length, a/W

Fig. 10 Mode I stress intensity range, $\Delta K_{\mathrm{I}}$, as a function of the normalized crack length $a / W$, obtained by the regression method, analytical model and ASTM E647: a regressed results at $T=25^{\circ} \mathrm{C}$,

in fracture experiments [30], that is the SMA exhibits a fracture toughness increase with increasing the testing temperature. Unfortunately, standard methods based on linear elastic and/or elastic plastic theories are not capable of capturing the effects of temperature and, therefore, they fail in the analysis of both static and fatigue cracks.

To this aim, fatigue crack propagation data were analyzed by the DIC regression method and the analytical model, as described in previous sections. Figure 10 reports the evolution of the stress intensity range $\left(\Delta K_{\mathrm{I}}\right)$, as a function of the normalized crack length $(a / W)$ as obtained from the regression method, analytical model and ASTM E647. Figure 10a reports the data obtained by the regression method at the three testing temperatures $\left(25^{\circ} \mathrm{C}, 45^{\circ} \mathrm{C}\right.$, and $\left.65^{\circ} \mathrm{C}\right)$, while Fig. $10 \mathrm{~b}$ and $\mathrm{c}$ illustrate direct comparisons between the different methods at $25{ }^{\circ} \mathrm{C}, 45{ }^{\circ} \mathrm{C}$, and $65{ }^{\circ} \mathrm{C}$, respectively.

Figure 10.a shows that the effective SIF range is mainly unaffected by the testing temperature for small cracks (al $W<0.4)$ whereas the temperature effects become $45^{\circ} \mathrm{C}$, and $65{ }^{\circ} \mathrm{C}$; b comparison at $T=25^{\circ} \mathrm{C}$; c comparison at $T=45^{\circ} \mathrm{C} ; \mathbf{d}$ comparison at $T=65{ }^{\circ} \mathrm{C}$

significant when increasing the crack extent. In particular, the lower the temperature the higher the SIF range, due to the increased near crack tip transformation zone and effective crack length. These effects are well captured by the analytical model, as shown in Fig. 10b-d. In fact, regressed data and analytical model always provide similar results whereas LEFM fails by a large amount especially at low temperature $\left(25^{\circ} \mathrm{C}\right)$ and large crack lengths $(a / W>0.5)$. Differences tend to vanish when increasing the testing temperature, as shown in Fig. 10d, because the material approaches the linear elastic solution due to the Clausius-Clapeyron relation, i.e., to the marked increase of the transformation stress.

\section{Crack Growth Rate}

Figures 11 show the crack propagations curves $(d a / d N$ versus $\Delta K_{\mathrm{I}}$ ) for the three testing temperatures, as obtained from the non-linear regression method (Fig. 11a), ASTM E647 (Fig. 11b) and by our analytical method (Fig. 11c). 


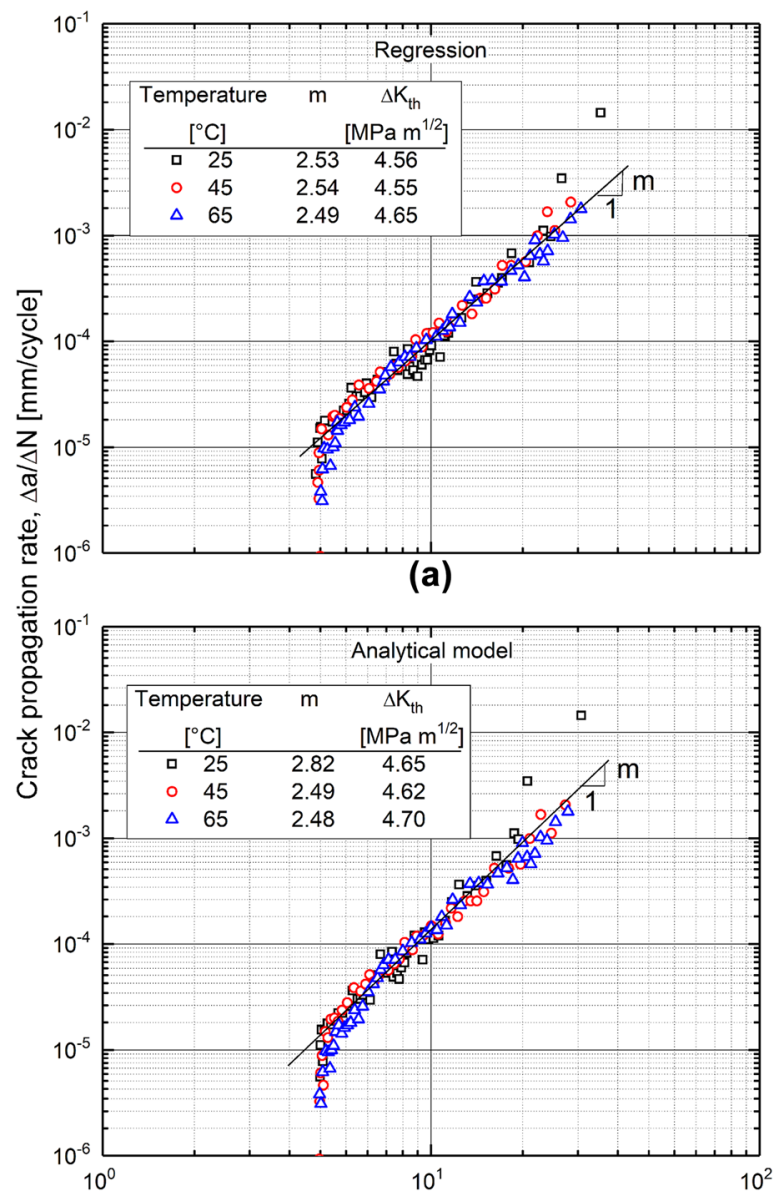

(c)

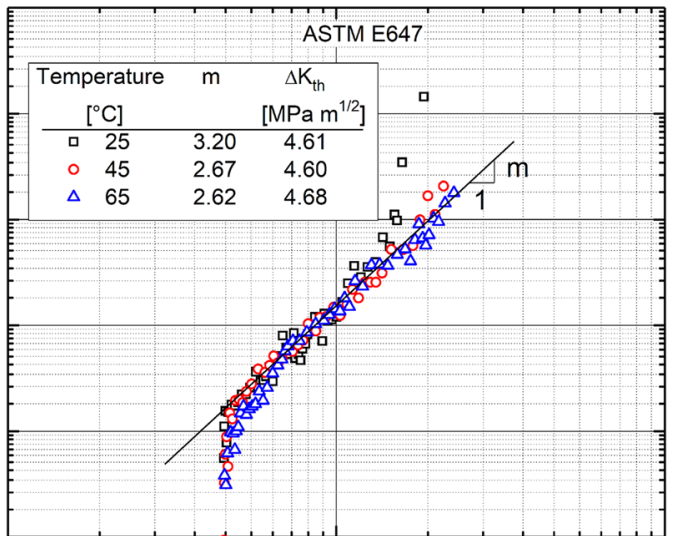

(b)

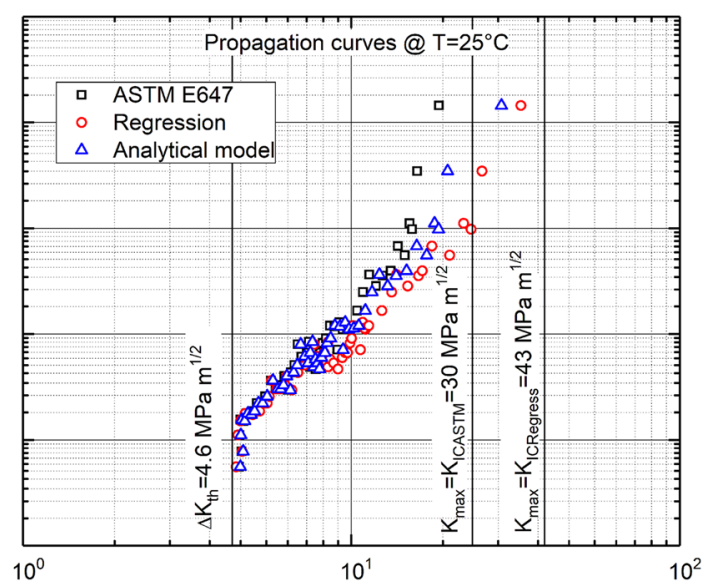

(d)

Fig. 11 Crack propagation curves $\Delta a / \Delta N$ vs. $\Delta K_{\mathrm{I}}$ obtained at the three testing temperatures $\left(25^{\circ} \mathrm{C}, 45^{\circ} \mathrm{C}\right.$ and $\left.65{ }^{\circ} \mathrm{C}\right)$ : a regressed results; b ASTM E647 results; c analytical results; $\mathbf{d}$ comparison between the three solutions at $25{ }^{\circ} \mathrm{C}$

In addition, propagation data, within the steady state regime, were fitted to the Paris law $\left(\mathrm{d} a / \mathrm{d} N=C \Delta K_{\mathrm{I}}^{m}\right)$. The values of the exponent $m$ and of the threshold stress intensity range $\left(\Delta K_{\mathrm{th}}\right)$ are also reported in the figures.

Figure 11d illustrates a direct comparison between the three methods at $T=25^{\circ} \mathrm{C}$, that is the condition with the largest differences between effective SIF and ASTM E647 results (see Fig. $10 \mathrm{~b})$. The critical conditions $\left(K_{\mathrm{Imax}}=K_{I C}\right)$ obtained in previous fracture experiments [30], for the same values of the testing temperature, are also shown in Fig. 11d. A good agreement with previous results was observed, that is propagation data approach the vertical asymptotes obtained from fracture experiment. In fact, LEFM results tend to the critical SIF obtained by ASTM E647 at $25^{\circ} \mathrm{C}\left(30 \mathrm{MPa} \mathrm{m}{ }^{1 / 2}\right)$ while regressed and analytical results approach the effective value of the critical SIF (43 $\mathrm{MPa} \mathrm{m}^{1 / 2}$ ).

On the contrary, negligible differences between the three methods are observed in the near threshold region, due to the reduced crack tip transformation zone and, consequently, to the predominantly elastic conditions.

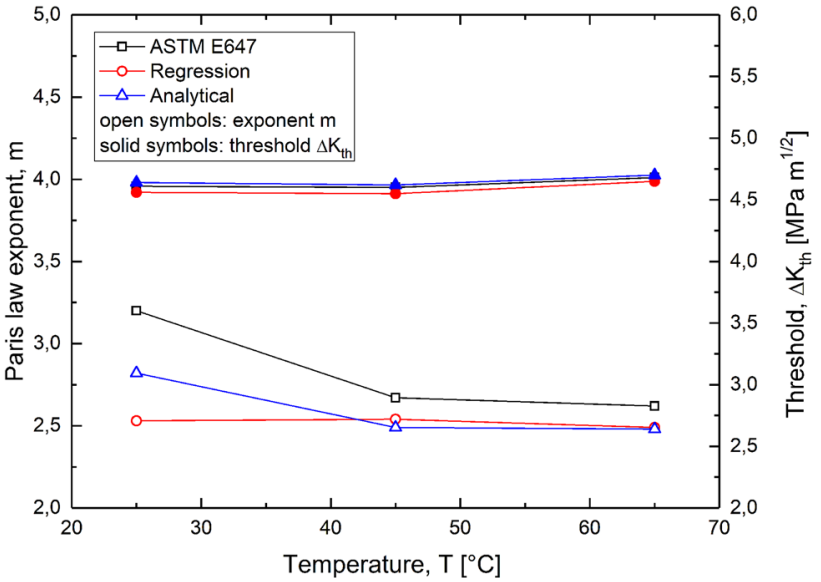

Fig. 12 SIF threshold $\left(\Delta K_{\text {th }}\right)$ and Paris law exponent $(m)$ as a function of the testing temperature: comparison between results from ASTM E647, analytical and regression methods

The effects of temperature on the values of the Paris law exponent and threshold SIF ( $m$ and $\Delta K_{\mathrm{th}}$ ) are summarized in Fig. 12. It was found that the three methods provide similar 
results on the SIF threshold, as also shown in Fig. 11d. In addition, this latter can be considered as a temperature independent parameter, with an average value around 4.6 $\mathrm{MPa} \mathrm{m}{ }^{1 / 2}$. This is the expected result because non-linear effects in the near threshold region, due to stress-induced crack tip transformations, become negligible. Furthermore, the obtained value is within the wide dispersion band obtained from previous experiments, as reported in the review paper [4]. In fact, values ranging from 1.9 to $5.4 \mathrm{MPa} \mathrm{m}^{1 / 2}$ are reported in [4] for pseudolastic NiTi. This large range is attributed to several material and testing factors affecting the crack tip transformation mechanisms, including the material composition, crystalline texture, transformation temperature, testing temperature, loading frequency, loading ratio, testing environment, specimen geometry etc. In addition, most of these parameters are not independent due to the marked thermo-mechanical coupling in SMAs.

Results on the exponent $m$ show a different trend with respect to $\Delta K_{\text {th }}$, i.e., with significant differences between the three prediction methods. In fact, regressed data are temperature independent, with an average value around 2.5. On the contrary, marked temperature effects are observed from the predictions of ASTM E647, that is $m$ decreases when increasing the testing temperature, from about 3.2 at $25^{\circ} \mathrm{C}$ to 2.7 and 2.6 at $45^{\circ} \mathrm{C}$ and $65^{\circ} \mathrm{C}$, respectively. The analytical model provides very similar results to the regression method at $45^{\circ} \mathrm{C}$ and $65^{\circ} \mathrm{C}$ whereas a slightly higher value, around 2.8 , was captured at $25^{\circ} \mathrm{C}$. This is attributed to the marked non-linearity occurring at $25^{\circ} \mathrm{C}$, that is the assumptions of small-scale transformation [50] become not fully satisfied.

The results summarized in Fig. 12 are again in agreement with those obtained from monotonic fracture experiments [30]. In fact, it was found that fatigue crack propagation in NiTi is significantly affected by the testing temperature within the pseudoelastic regime $\left(A_{\mathrm{f}}<T<M_{\mathrm{d}}\right)$. In particular, the higher the temperature the longer the fatigue life (see Fig. 9) and a similar effect was observed on the critical SIF [30]. However, it was demonstrated that this trend cannot be attributed to a change in the material properties, but to the effects of temperature on the near crack tip stress-strain distribution. Actually, crack always grows in the high stress detwinned martensitic phase, as also experimentally observed by SEM investigations in [22]. As a consequence, crack propagation curves become temperature independent if considering the effective SIF range obtained from DIC experiments. This is also in agreement with the predictions of our analytical model, even if some limitations were observed at the lowest value of the temperature. The model is able to correctly capture the effects of complex thermo-mechanical loading conditions in SMAs, i.e., in terms of applied stress and temperature.

In conclusion, a novel approach should be adopted for defining crack propagation parameters in pseudoelastic
SMAs, because temperature significantly affects the effective SIF range and, consequently, both applied stress and temperature should be considered as loading parameters.

\section{Conclusions}

Temperature effects on fatigue crack propagation in austenitic NiTi SMAs, within the pseudoelastic regime, were analyzed. Three different methods were applied to analyze the crack propagation bahavior: (1) the standard ASTM E647 method, (2) a recent analytical method by Maletta et al. [47, 48] and (3) a regression method based on the DIC displacement field. Results obtained from the three methods were systematically analyzed and discussed. The main outcomes can be summarized as follows:

- Significant effects of the temperature were observed on the fatigue crack propagation behavior, within the stable crack propagation regime. The higher the temperature the higher the cycles to failure and the lower the crack propagation rate.

- Crack propagation curves ( $\mathrm{d} a / \mathrm{d} N$ versus $\Delta K_{\mathrm{I}}$ ) obtained from ASTM E647 method, are significantly different with respect to those obtained from regression of DIC data. In fact, ASTM curves are significantly affected by the testing temperature, i.e., the lower the temperature the higher the Paris law exponent. On the contrary, effective crack propagation curves, that are obtained from the regression method, become temperature independent.

- Good agreements were observed between analytical and regressed results, i.e., both provide temperature independent crack propagation curves. The methods give similar values of the Paris law exponent.

- Both mechanical load and temperature have to be considered to describe stable crack growth in SMAs, i.e., special methods have to be used to calculate the effective stress intensity range. This allows to consider temperature independent crack propagation parameters of the material. Similar results were obtained in previous fracture mechanics studies.

- On the contrary, near threshold behavior was found to be unaffected by the testing temperature and similar results were obtained from the three methods. This is a direct consequence of the negligible crack tip nonlinearity occurring in the near threshold region, i.e., it is due to the reduced SIF and small transformation region. This is an important result and it suggests that highcycle fatigue response of SMAs is temperature insensitive, within the pseudoelastic regime.

- Future studies will be aimed at analyzing the effects of temperature on fatigue crack propagation in martensitic SMAs. 


\section{References}

1. Otsuka K, Ren X (2005) Physical metallurgy of Ti-Ni-based shape memory alloys. Progr Mater Sci 50:511-678

2. Duerig T, Pelton A, Stockel D (1999) An overview of nitinol medical applications. Mater Sci Eng A 273-275:149-160

3. Jani JM, Leary M, Subic A, Gibson MA (2014) A review of shape memory alloy research, applications and opportunities. Mater Des 56:1078-1113

4. Robertson SW, Pelton AR, Ritchie RO (2012) Mechanical fatigue and fracture of nitinol. Int Mater Rev 57(1):1-37

5. Mahtabi MJ, Shamsaei N, Mitchell MR (2015) Fatigue of nitinol: the state-of-the-art and ongoing challenges. J Mech Behav Biomed Mater 50:228-254

6. Kang G, Song D (2015) Review on structural fatigue of NiTi shape memory alloys: pure mechanical and thermo-mechanical ones. Theor Appl Mech Lett 5:245-254

7. Moumni Z, Zhang Y, Wang J (2018) Global approach for the fatigue of shape memory alloys. Shape Mem Superelast 4(4):385-401

8. Sawaguchi T, Kaustrater G, Yawny A, Wagner M, Eggeler G (2003) Crack initiation and propagation in 50.9 at. pct Ni-Ti pseudoelastic shape-memory wires in bending-rotation fatigue. Metall Mater Trans A 34:2847

9. Runciman A, Xu D, Pelton AR, Ritchie RO (2011) An equivalent strain/Coffin-Manson approach to multiaxial fatigue and life prediction in superelastic nitinol medical devices. Biomaterials 32:4987-4993

10. Maletta C, Sgambitterra E, Furgiuele F, Casati R, Tuissi A (2012) Fatigue of pseudoelastic NiTi within the stress-induced transformation regime: a modified Coffin-Manson approach. Smart Mater Struct 21(11):112001

11. Maletta C, Sgambitterra E, Furgiuele F, Casati R, Tuissi A (2014) Fatigue properties of a pseudoelastic NiTi alloy: strain ratcheting and hysteresis under cyclic tensile loading. Int J Fatigue 66:78-85

12. Song D, Kang G, Kan Q, Yu C, Zhang C (2015) Non-proportional multiaxial whole-life transformation ratchetting and fatigue failure of super-elastic NiTi shape memory alloy micro-tubes. Int J Fatigue 80:372-380

13. Alarcon E, Heller L, Chirani SA, Šittner P, Kopecek J, Saint-Sulpice L, Calloch S (2017) Fatigue performance of superelastic NiTi near stress-induced martensitic transformation. Int J Fatigue 95:76-89

14. Wu Y, Ojha A, Patriarca L, Sehitoglu H (2015) Fatigue Crack Growth Fundamentals in Shape Memory Alloys. Shape Memory and Superelasticity 1(1):18-40

15. Chowdhury P, Sehitoglu H (2016) Mechanisms of fatigue crack growth-a critical digest of theoretical developments. Fatigue Fract Eng Mater Struct 39:652-674

16. Baxevanis T, Lagoudas DC (2015) Fracture mechanics of shape memory alloys: review and perspectives. Int J Frac 191:191-213

17. Robertson SW, Ritchie RO (2007) In vitro fatigue-crack growth and fracture toughness behavior of thin-walled superelastic Nitinol tube for endovascular stents: a basis for defining the effect of crack-like defects. Biomaterials 28:700-709

18. Robertson SW, Ritchie RO (2008) A fracture-mechanics-based approach to fracture control in biomedical devices manufactured from superelastic nitinol tube. J Biomed Mater Res Part B Appl Biomater 84:26-33

19. McKelvey AL, Ritchie RO (1999) Fatigue-crack propagation in Nitinol, a shape-memory and superelastic endovascular stent material. J Biomed Mater Res 47:301-308

20. Robertson SW, Mehta A, Pelton AR, Ritchie RO (2007) Evolution of crack-tip transformation zones in superelastic Nitinol subjected to in situ fatigue: a fracture mechanics and synchrotron X-ray microdiffraction analysis. Acta Mater 55:6198-6207
21. Daymond MR, Young ML, Almer JD, Dunand DC (2007) Strain and texture evolution during mechanical loading of a crack tip in martensitic shape-memory NiTi. Acta Mater 55:3929-3942

22. Gollerthan S, Young ML, Baruj A, Frenzel J, Schmahl WW, Eggeler G (2009) Fracture mechanics and microstructure in NiTi shape memory alloys. Acta Mater 57:1015-1025

23. Ungár T, Frenzel J, Gollerthan S, Ribárik G, Balogh L, Eggeler G (2017) On the competition between the stress-induced formation of martensite and dislocation plasticity during crack propagation in pseudoelastic NiTi shape memory alloys. J Mater Res 32(23):4433

24. Young ML, Gollerthan S, Baruj A, Frenzel J, Schmahl WW, Eggeler G (2013) Strain mapping of crack extension in pseudoelastic NiTi shape memory alloys during static loading. Acta Mater 61(15):5800-5806

25. Gollerthan S, Young ML, Neuking K, Ramamurty U, Eggeler G (2009) Direct physical evidence for the back-transformation of stress-induced martensite in the vicinity of cracks in pseudoelastic NiTi shape memory alloys. Acta Mater 57:5892-5897

26. Maletta C, Bruno L, Corigliano P, Crupi V, Guglielmino E (2014) Crack-tip thermal and mechanical hysteresis in shape memory alloys under fatigue loading. Mater Sci Eng A 616:281

27. Daly S, Miller A, Ravichandran G, Bhattacharya K (2007) Experimental investigation of crack initiation in thin sheets of nitinol. Acta Mater 55:6322-6330

28. Sgambitterra E, Maletta C, Furgiuele F (2015) Investigation on crack tip transformation in NiTi alloys: effect of the temperature. Shap Mem Superelast 1:275-283

29. Sgambitterra E, Lesci S, Maletta C (2015) Effects of higher order terms in fracture mechanics of shape memory alloys by digital image correlation. Procedia Eng 109:457-464

30. Maletta C, Sgambitterra E, Niccoli F (2016) Temperature dependent fracture properties of shape memory alloys: novel findings and a comprehensive model. Sci Rep 6:17

31. Sgambitterra E, Bruno L, Maletta C (2014) Stress induced martensite at the crack tip in NiTi alloys during fatigue loading. Fratt ed Integr Strutt 30:167-173

32. Sgambitterra E, Maletta C, Furgiuele F, Sehitoglu H (2018) Fatigue crack propagation in $\left[\begin{array}{lll}0 & 1 & 2\end{array}\right]$ NiTi single crystal alloy. Int J Fatigue 112:9-20

33. Broek D (1986) elementary engineering fracture mechanics, 4th edn. Kluwer Academic Publisher, Dordrecht

34. Sgambitterra E, Maletta C, Furgiuele F (2015) Temperature dependent local phase transformation in shape memory alloys by nanoindentation. Scr Mater 101:64-67

35. Maletta C, Niccoli F, Sgambitterra E, Furgiuele F (2017) Analysis of fatigue damage in shape memory alloys by nanoindentation. Mater Sci Eng A 684:335-343

36. Wang GZ, Xuan FZ, Tu ST, Wang ZD (2010) Effects of triaxial stress on martensite transformation, stress-strain and failure behavior in front of crack tips in shape memory alloy NiTi. Mater Sci Eng A 527:1529-1536

37. Hazar S, Anlas G, Moumni Z (2016) Evaluation of transformation region around crack tip in shape memory alloys. Int J Fract 197:99-110

38. Ardakani SH, Afshar A, Mohammadi S (2016) Numerical study of thermo-mechanical coupling effects on crack tip fields of mixed-mode fracture in pseudoelastic shape memory alloys. Int J Solids Struct 81(1):160-178

39. Maletta C, Falvo A, Furgiuele F, Leonardi A (2009) Stress-induced martensitic transformation in the crack tip region of a NiTi alloy. J Mater Eng Perform 18:679-685

40. Maletta C, Sgambitterra E, Furgiuele F (2013) Crack tip stress distribution and stress intensity factor in shape memory alloys. Fatigue Fract Eng Mater Struct 36(9):903-912 
41. Baxevanis T, Chemisky Y, Lagoudas DC (2012) Finite element analysis of the plane strain crack-tip mechanical fields in pseudoelastic shape memory alloys. Smart Mater Struct 21(9):094012

42. Freed Y, Banks-Sills L (2007) Crack growth resistance of shape memory alloys by means of a cohesive zone model. J Mech Phys Solids 55:2157-2180

43. Jape S, Baxevanis T, Lagoudas DC (2018) On the fracture toughness and stable crack growth in shape memory alloy actuators in the presence of transformation-induced plasticity. Int $\mathbf{J}$ Fract 209:117-130

44. Birman V (1998) On mode I fracture of shape memory alloy plates. Smart Mater Struct 7:433-437

45. Lexcellent C, Thiebaud F (2008) Determination of the phase transformation zone at a crack tip in a shape memory alloy exhibiting asymmetry between tension and compression. Scr Mater 59:321-323

46. Lexcellent C, Laydi MR, Taillebot V (2011) Analytical prediction of the phase transformation onset zone at a crack tip of a shape memory alloy exhibiting asymmetry between tension and compression. Int J Fract 169:1-13

47. Maletta C, Furgiuele F (2010) Analytical modeling of stressinduced martensitic transformation in the crack tip region of nickel-titanium alloys. Acta Mater 58:92-101
48. Maletta C (2012) A novel fracture mechanics approach for shape memory alloys with trilinear stress-strain behavior. Int J Fract 177:39-51

49. Baxevanis T, Lagoudas DC (2012) A mode I fracture analysis of a center-cracked infinite shape memory alloy plate under plane stress. Int J Fract 175:151

50. Maletta C, Furgiuele F (2011) Fracture control parameters for NiTi based shape memory alloys. Int J Solids Struct 48(11-12): $1658-1664$

51. Baxevanis T, Landis CM, Lagoudas DC (2014) On the Effect of latent heat on the fracture toughness of pseudoelastic shape memory alloys. J Appl Mech 81:101006

52. You Y, Zhang Y, Moumni Z, Anlas G, Zhang W (2017) Effect of the thermomechanical coupling on fatigue crack propagation in NiTi shape memory alloys. Mater Sci Eng A 685:50-56

53. ASTM E647, standard test method for measurement of fatigue crack growth rates

Publisher's Note Springer Nature remains neutral with regard to jurisdictional claims in published maps and institutional affiliations. 